\title{
Coanálise do trabalho em uma UTI pediátrica: relato de experiência de construção de um dispositivo ergológico
}

\section{Co-analysis of work in a pediatric ICU: report of experience in the construction of an ergological device}

\section{Coanálisis del trabajo en una UTI pediátrica: relato de experiência de construcción de un dispositivo ergológico}

Cirlene de Souza Christo ${ }^{1}$

Lilian Landim Syrio ${ }^{2}$

Nathália Silva Prado ${ }^{3}$

\begin{abstract}
RESUMO: Neste artigo discutem-se os resultados de uma experiência de intervenção realizada em ação de extensão universitária em um hospital pediátrico da rede pública de saúde, localizado na cidade do Rio de Janeiro. A problemática demandada para análise foi o sofrimento psíquico relacionável ao trabalho em UTI. Com base nos referenciais da Ergologia, procedeu-se à construção de um dispositivo de intervenção, denominado Encontros sobre o Trabalho, com vistas à coanálise e transformação das condições e organização do trabalho no sentido da promoção da saúde dos trabalhadores. Identificam-se algumas regras de ofício e estratégias produzidas pelos profissionais individual e coletivamente. Tecem-se considerações sobre o processo de construção, as dificuldades de operacionalização e potencialidades do dispositivo construído.
\end{abstract}

Palavras-chave: Trabalho em saúde. UTI pediátrica. Ergologia.

ABSTRACT: This article discusses the results of an intervention experiment performed within a university extension action. It tookplace in a pediatric hospital of the public health system in

\footnotetext{
1 Doutora em Psicologia Social, Professora adjunta Departamento de Psicologia Social, Universidade Federal do Rio de Janeirocirlenechr@gmail.com

2 Psicóloga, Universidade Federal do Rio de Janeiro, bolsista na edição 2017 do Programa Institucional de Fomento Único de Ações de Extensão (PROFAEx / UFRJ) - lilian_syrio@hotmail.com

3 Graduanda em Psicologia, Universidade Federal do Rio de Janeiro, bolsista na edição 2017 do Programa Institucional de Fomento Único de Ações de Extensão (PROFAEx / UFRJ) - natprado2@gmail.com
} 
Rio de Janeiro. The problem under analysis was the psychic suffering from the work in the ICU. Based on Ergology benchmarks, we made an intervention device, called "Meetings on Work". The aim of such a device was the co-analysis and transformation of the work conditions. Besides, another objective was the organization of work to promote workers' health. We identified some rules and strategies created individually and collectively by the professionals. Finally, we make considerations about the construction process, operationalization difficulties and potentialities of the device.

Keywords: Health work. Pediatric ICU. Ergology.

RESUMEN: Este artículo aborda los resultados de un experimento de intervención realizado em una acción de extensión universitária. Tuvo lugar e nun hospital pediátrico del sistema de salud pública, ubicado en la ciudad de Río de Janeiro. El problema que se estaba analizando era el sufrimiento psíquico del trabajo en la UCI. Basándonos en los puntos de referencia de la Ergología, cream o sun dispositivo de intervención, llamado "Encuentros de Trabajo". El objetivo de tal dispositivo era elco-análisis y latransformación de las condiciones de trabajo. Además, otro objetivo era la organización del trabajo para promover la salud de los trabajadores. Identificamos algunas reglas y estrategias laboral escreadas individual y colectivamente por los profesionales. Por último, hacemos consideraciones sobre el proceso de construcción, las dificultades de operacionalización y las potencialidades del dispositivo.

Palabras clave: Trabajo en salud. UTI pediátrica.Ergología.

\section{INTRODUÇÃO}

A experiência aqui relatada é a de uma ação de extensão da qual participaram estudantes de graduação em Psicologia ${ }^{4}$. O objetivo foi construir, com os profissionais de saúde que atuavam em uma Unidade de Terapia Intensiva (UTI) de um hospital pediátrico da rede pública de saúde na cidade do Rio de Janeiro, um dispositivo coletivo de coanálise do trabalho com vistas a compreender e transformar as relações entre o trabalho_em suas condições e modo de organização e a saúde dos profissionais em questão. A escolha do local de desenvolvimento da ação de extensão se deu a partir de indicações pelo setor de psicologia do hospital de queixas por parte desses profissionais de sofrimento psíquico relacionável ao trabalho na UTI, especialmente pela iminência de agravamentos do quadro de saúde e de perda de pacientes por morte.

Compreender, do ponto de vista dos profissionais, os fatores que contribuiriam para esse possível sofrimento foi o propósito da intervenção. Como ponto de partida, buscou-se na literatura científica especializada, alguns norteadores para a análise.

Segundo Baasch e Laner (2011) ${ }^{1}$, o sofrimento no trabalho em UTI pode decorrer do sofrimento

4 Dentre eles, duas estudantes eram bolsistas na edição 2017 do Programa Institucional de Fomento Único de Ações de Extensão (PROFAEx) da Universidade Federal do Rio de Janeiro.

Tempus, actas de saúde colet, Brasília, 13(2), 247-261, jun, 2019.

ISSN 1982-8829 
alheio, especialmente quando a sua possibilidade de proporcionar alívio é limitada, tanto em termos de condições e limites pessoais, como pelo ambiente de trabalho ou pelo tipo de patologia do paciente.

Pesquisas apontam que para além da constante oscilação entre sucesso e fracasso e da tensão pela possibilidade de perda do paciente, há que se considerar um quadro complexo de exigências impostas aos profissionais de saúde que atuam em UTI. Segundo alguns pesquisadores, esse quadro contribui para o desgaste físico e emocional desses profissionais, em função da necessidade de realização de procedimentos complexos e intenso ritmo de trabalho ${ }^{2}$; da limitação do acesso a recursos tecnológicos e de dificuldades de desenvolver um processo de trabalho humanizado ${ }^{3}$; dos tipos de movimentos realizados nas atividades de trabalho dos profissionais de enfermagem ${ }^{4}$; assim como da sobrecarga de trabalho por superlotação, falta de preparo da equipe técnica e espaço físico inadequado 5 .

É de se supor que quadros como esses exijam uma mobilização crescente das potencialidades corporais, cognitivas, afetivas e sociais dos profissionais de saúde nas situações concretas de trabalho. Mobilização essa que, além de tornar possível a eficácia e a qualidade do serviço, pode interagir (de forma negativa ou positiva) com a saúde dos trabalhadores ${ }^{6}$. Numa segunda via, Masson, Gomes e Brito ${ }^{7}$ apontam também para o caráter desafiante, criativo e produtor de saúde das atividades de trabalho em uma UTI.

A perspectiva de análise sobre as relações trabalho e saúde adotada pelas autoras é coerente com o nosso pressuposto, a partir de Canguilhem ${ }^{8,9}$, de que a saúde não se limita à simples ausência de doença, mas é resultante de um debate (uma luta ou embate) sempre renovado entre normas anônimas provindas do meio e normas que cada ser produz no confronto com o meio natural e social. O autor argumenta que como ser sujeito de suas normas é condição fundamental para a vida do homem, a atividade humana - como essa busca, essa disposição e possibilidade do vivente humano de produzir normas ${ }^{7}$ - é um exercício de saúde, uma expressão da vida humana.

Analisando e desenvolvendo esse conceito de atividade como oposição à inércia e à indiferença, Schwartz ${ }^{10}$ propõe aplicá-lo à vida no trabalho. Para ele, o trabalhar envolve sempre um risco, visto que implica em, "de alguma forma, colocar à prova do real seus próprios limites, suas próprias capacidades" 11 , assim como fazer escolhas de si mesmo. A atividade, segundo ele, se dá em uma dinâmica de contradições potenciais, um lugar em que são travados debates entre normas antecedentes e tendências a renormatizações. Entendida como o resultado das microescolhas realizadas no curso da gestão nas atividades de trabalho, a noção de renormatização é assim tomada por referência à potência humana de fazer a gestão do vai-e-vem entre a ordem do estabelecido, a norma, e a tendência ao agir em aderência no aqui e agora ${ }^{12}$. Como este gerir se faz por intermédio de cada pessoa, de cada protagonista do trabalho, de vidas singulares, cada ser humano introduziria permanentemente algo de si na situação de trabalho. Esse uso de si que, segundo o autor, além de se fazer pelos outros $^{12}$, pela heterodeterminação das normas, prescrições e valores constituídos historicamente, 
se faztambém por si, pela afirmação de normas e valores próprios, via renormatização, na criação de estratégias singulares para enfrentar os desafios do seu meio..Evitando a noção mais comum de subjetividade, Schwartz ${ }^{11}$ denomina este $s i$ - que transita entre o individual e o coletivo - de "corpo-si”, o qual incluiria a inteligência do corpo, com suas economias e sinalizações sensoriais, não conscientes e, portanto, muito difíceis de serem verbalizadas.

Assim, tomando-se como princípio que a eficácia e a saúde não são a priori uma evidência tangível e que a atividade e os saberes mobilizados para a realização do trabalho não são totalmente explícitos, buscou-se construir com os profissionais que trabalham nessa UTI, a partir do referencial da Ergologia, um dispositivo que contribuísse para a ampliação das alternativas de escolhas em suas atividades de trabalho. Os propósitos foram: (a) identificar os problemas relacionados ao trabalho que pudessem se constituir como fonte de sofrimento; (b) dar visibilidade aos debates de normas nas situações concretas de trabalho e às tentativas de reinterpretação ou proposição de outras normas pelos protagonistas do trabalho em análise; e (c) ampliar os recursos particulares e coletivos a serem mobilizados em situações de trabalho futuras.

No entanto, a construção do dispositivo deveria observar coerência com alguns princípios adotados no campo da saúde do trabalhador: o de privilegiar a análise da conformação concreta do processo de trabalho, tanto em sua vertente técnica como social ${ }^{13}$; o de que a luta pela saúde é uma conquista permanente, engendrada no dia-a-dia, com a participação ativa dos trabalhadores na produção de conhecimento e transformação do trabalho ${ }^{14}$; assim como o da necessidade de diálogo entre os saberes das diversas disciplinas científicas e os advindos das experiências dos coletivos de trabalhadores, sustentado tanto por exigências éticas, de respeito entre os participantes e seus saberes, quanto por exigências epistemológicas, de respeito ao lugar privilegiado do conceito de atividade, e da geração de novos saberes e valores por um processo de coprodução de conhecimentos ${ }^{15}$.

O objetivo desse artigo é relatar e discutir os objetivos, bases teórico-metodológicas e resultados dessa ação de extensão, tecendo considerações sobre a construção e o alcance do dispositivo de coanálise do trabalho construído, assim como as dificuldades encontradas em sua operacionalização.

\section{MÉTODO E CONSTRUÇÃO DO DISPOSITIVO}

O dispositivo foi inspirado nos "Encontros sobre o Trabalho" (EsT) propostos pela démarche ergológica $^{11,16}$. O propósito era a instauração de um processo de análise conjunta acerca da distância entre as atividades de trabalho e as prescrições e normas que as antecedem que permitisse umdiálogo-debate crítico acerca das condições e modos de organização do trabalho. Visando a explicitar os debates de normas e valores que circulam nas atividades de trabalho, a estratégia usada para o estímulo às verbalizações da experiência foi a descrição oral pelos graduandos de situações concretas de trabalho observadas e/ou relatadas em entrevistas em fase preliminar aos EsT. 
As atividades da ação de extensão na UTI iniciaram-se em abril de 2017. Participaram dela quatro graduandos de psicologia, com orientação da primeira autora, e 32 profissionais de saúde que atuavam na referida UTI. A aproximação dos estudantes aos profissionais se deu via direção do hospital e chefias médica e de enfermagem da UTI. Elas tiveram um papel importante na comunicação formal sobre a presença e objetivos dos estudantes no setor durante a jornada de trabalho, assim como na viabilização de espaço físico e organização da escala de trabalho para a realização dos EsT.

Com vistas à construção conjunta dos objetivos e do dispositivo de intervenção, optou-se por iniciar com uma aproximação gradual às informações sobre o trabalho tal como prescrito, às normas de funcionamento da UTI, assim como aos profissionais que lá atuavam.

Pretendia-se identificar possíveis situações críticas e temáticas pertinentes ao trabalho que pudessem interessar aos profissionais analisar e discutirc oletivamente. Nessa fase procedeu-se ao levantamento e análise de documentos, a observações livres do trabalho e a entrevistas individuais semiestruturadas. Dentre os documentos analisados figuraram: rotinas escritas do trabalho, legislação do exercício profissional, relatórios e escalas de serviço. A observação envolveu a realização de procedimentos junto aos pacientes, assim como as sessões, denominadas rounds, de discussão dos casos dos pacientes da UTI com a participação aberta a todos os profissionais que lá atuam (incluindo enfermeiros, técnicos, psicólogos, fisioterapeutas e nutricionistas), contando com maior frequência de médicos plantonistas e residentes.

Ao abordar os profissionais, os estudantes esclareciam acerca dos objetivos do projeto e dos princípios éticos que norteavam seu desenvolvimento (participação voluntária e não identificação dos participantes e da instituição), consultando-os verbalmente sobreo interesse em participar. Havendo resposta positiva, realizavam-se entrevistas semiestruturadas, com o auxílio de um roteiro, abordando as condições e a organização do trabalho na UTI, assim como as representações dos profissionais sobre a relação trabalho-saúde.

O roteiro abordava questões como: (a)as principais atividades exercidas na UTI; (b) os recursos disponíveis para a realização do trabalho, como protocolos, orientações, instalações e colaboração dos colegas; (c) as situações críticas em relação ao ambiente físico e social de trabalho; (d) as possíveis mudanças recentes no trabalho; (e) as exigências e ritmo de trabalho; e (f) a relação com os pacientes e familiares. Quinze profissionais foram entrevistados. Dentre eles, dois médicos plantonistas, dois médicos residentes, dois enfermeiros, sete técnicos de enfermagem e dois faxineiros.

Os dados registrados nos diários de campo e nas anotações das entrevistas pelos graduandos de psicologia foram alvo de sucessivas análises e sessões de discussão com a coordenadora do projeto. Buscando privilegiar as temáticas mais recorrentes, definiram-se três temas geradores para os EsT: (1) a relação com pacientes e familiares, envolvendo questões relativas aos vínculos afetivos 
que se formam, assim como à convivência cotidiana; (2) a saúde de quem trabalha, envolvendo questões como intensidade e ritmo do trabalho, problemas de saúde relacionáveis ao trabalho e estratégias de proteção e cuidado de si; e (3) o trabalho coletivo na UTI, envolvendo as relações interpessoais e hierárquicas, o trabalho multiprofissional e interequipes na UTI. Com o intuito de acessar os profissionais dos três plantões diurnos ${ }^{5}$, realizaram-se em três dias diferentes reuniões de apresentações da proposta dos EsT, com negociação acerca dos objetivos, dos temas a serem abordados, assim como das datas e horários mais adequáveis às escalas e rotina do setor. Apesar de serem incentivados, os profissionais da UTI não propuseram outros temas.

Os EsT foram realizados entre os dias 10 e 30 de agosto de 2017. Das nove datas planejadas, foi possível a realização dos encontros em cinco, com presença em torno de cinco profissionais da UTI, havendo variação desse número no primeiro e no último encontro, com doze e três participantes, respectivamente. Todos tiveram duração de uma hora, no turno diurno na sala de realização dos rounds, situada no interior da UTI. Houve variação também entre os participantes em função da disponibilidade dos profissionais nos dias de cada encontro, seja por motivo de escala de plantões, por falta de substituto para o trabalho no horário do encontro, ou por não ter interesse em participar.

Nas quatro datas após o terceiro encontro, os EsT não aconteceram por não comparecimento dos profissionais. Na primeira, os graduandos tiveram contato apenas com três residentes que não demonstraram interesse. $\mathrm{Na}$ segunda, dois médicos tentaram chamar os profissionais, mas não tiveram resposta. A partir do comentário de um residente de que "o dia está um pouco esquisito", obteve-se a informação de que naqueles dias a UTI estava operando acima de sua capacidade normal. Nos encontros realizados nas duas datas subsequentes, os profissionais informaram sobre uma mudança organizacional, cuja necessidade teria sido atribuída ao aumento de demanda do serviço hospitalar público em função da crise econômica. Segundo eles, dois leitos, antes reservados para cirurgias esporádicas, tinham sido ocupados permanentemente, aumentando o volume de trabalho da equipe, sem aumento no efetivo de profissionais. Após essas datas, teve-se a mesma dificuldade de reunir os profissionais por mais duas. Agendou-se uma décima data, mas com mais um encontro não realizado por falta de quórum. Sem uma posição coletiva sobre o interesse e possibilidade de manter os EsT, optou-se por enviar uma comunicação de disponibilidade dos graduandos em dar continuidade ao projeto, mas até o final do prazo previsto, não houve manifestação de interesse por parte dos profissionais.

Todos os EsT foram realizados com a presença de pelo menos dois estudantes extensionistas, que dividiam as tarefas de coordenar os diálogos-debates e de fazer o registro dos materiais discursivos produzidos. Por ter sido feito o registro de forma manual, não foi possível registrar todas as falas durante os diálogos nos EsT, privilegiando-se as consideradas mais relevantes.

5 Devido a limitações de carga horária e locomoção, não foi possível a presença dos extensionistas no hospital durante a noite ou no momento de troca de plantões, únicos períodos em que seria possível conversar com os profissionais dos plantões noturnos.

Tempus, actas de saúde colet, Brasília, 13(2), 247-261, jun, 2019. 


\section{RESULTADOS E DISCUSSÃO}

\section{Relações trabalho e saúde}

Sobre as condições de trabalho na UTI, a maioria dos profissionais entrevistados reiterou a disponibilidade de recursos técnicos para o trabalho. Todavia, tanto o espaço de trabalho quanto o de descanso foram adjetivados como confinados e restritos em referênciaà quantidade de leitos $\mathrm{e}$ de profissionais e responsáveis que os ocupam. O ritmo de trabalho foi qualificado como intenso e com variações em relação ao número de leitos ocupados e à gravidade do quadro dos pacientes. Essas questões, assim como a alimentação, foram debatidas pelos profissionais também nos EsT.

\section{Excerto dos diálogos no EsT 6:}

- Não sabemos nem se é dia ou noite, quando a gente sai parece que sai um peso, às vezes. Não vemos a luz do sol. - Além de não poder descansar o estar é minúsculo. Às vezes comemos de frente para o banheiro. Tem três horas de descanso na teoria, mas na prática nunca é isso. - Não dá tempo às vezes de ir ao banheiro ou comer tranquilo. Apenas o café e o almoço são as refeições certas, não tem lanche. - Já nos foi servida comida estragada no refeitório. - A fila do almoço é enorme e encurta o horário de uma hora de descanso.

Conforme relatado, ao longo do período de realização dos EsT, em função do aumento da demanda pelo serviço público de saúde, houve uma mudança no sistema de ocupações da UTI: dois leitos, antes reservados para pré e pós-cirurgia, passaram a ser ocupados permanentemente, gerando menor flexibilidade para os ajustes operados pelos profissionais na definição das escalas dos plantões, o que fazia com que as faltas fossem consideradas por vezes inevitáveis, aumentando a intensidade do trabalho dos presentes.

\section{Excerto dos diálogos no EsT 7:}

- À noite e aos finais de semana falta médico, ficando apenas um na UTI. Teve o caso de uma médica que estava grávida que teve contrações durante o plantão noturno e teve que esperar a troca de plantão para sair. (...) É comum que quem trabalha na UTI vá ao trabalho estando doente, com enxaqueca e etc. Eu mesma, um dia cheguei para trabalhar doente e fiquei alguns minutos tomando soro antes de começar o expediente.

Na maioria dos EsT, assim como nas entrevistas, houve relatos sobre implicações à saúde que os profissionais relacionaram ao trabalho. Desde dores de cabeça, alterações no sono, isolamento social, dores nas costas pelas posturas necessárias aos cuidados no leito, até os riscos de contaminação e de possíveis agressões por parte dos responsáveis, mesmo que na maioria das vezes restringindo-se a ameaças. Alguns relatam ser necessária uma atençãona conciliação entre 
avida no trabalho e a vida fora do trabalho, envolvendo estratégias de proteção e cuidado de si, mesmo que nem sempre suficientes em termos de preservação da saúde.

\section{Excerto dos diálogos no EsT 6:}

- Ultimamente rezamos, antigamente saíamos e fazíamos caminhadas, ajudava a espairecer, esquecer um pouco, agora vamos para casa por conta dos filhos. Mesmo as que não têm, trabalham muito. - Não espairecemos, f icamos com as questões. (...) - Vamos para casa e pensamos muito nos pacientes.

Além das estratégias individuais de proteção e cuidado, houve indicação de estratégias coletivas, como a combinação de um(a) profissional cobrir o(a) outro(a) no trabalho enquanto descansava. Todavia, indicam ter atualmente menos margem de liberdade para fazer esse tipo de gestão.

\section{Excerto dos diálogos no EsT 6:}

- Houve corte na flexibilização do horário de almoço de 1h para 1h30. - Mas também tem gente que abusa do descanso. - Por um todos pagam, pois alguns abusam dos pequenos descansos, antigamente era $1 \mathrm{~h} 30$ de descanso, esses $30 \mathrm{~min}$ fazem muita diferença. Antigamente trabalhávamos mais tranquilos, agora trabalhamos morrendo de sono.

No conflito produzido pela quebra dessa regra estabelecida pelo coletivo de trabalhadores, mesmo que não formalmente, abriu-se espaço para a imposição da regra oficial, produzida de forma distanciada das gestões cotidianas das atividades de trabalho. Segundo D. Cru ${ }^{17}$, mais do que tratar da dimensão técnica do trabalho, as regras do ofício balizam as relações sociais no trabalho, ajudando os membros do coletivo a se orientar. Em uma relação de indissociabilidade e coerência entre si, elas parecem garantir que o trabalho não seja perturbado por intervenções improvisadas. Isto não por formulações estereotipadas impostas ou transmitidas por repetição, mas produzidas em um agir e falar em referência a circunstâncias específicas. Note-se que a regra de cobertura do tempo de descanso entre os profissionais balizava essa ação de cuidado para além da regra formal, permitindo um fazer/viver junto que ampliava para todos a proteção à saúde. Apenas em sua quebra, em sua perda de capacidade de organizar o trabalho em sua dimensão real, produziuse, não sem custo, uma regra hierárquica que restringia a gestão desse aspecto do trabalho pelo coletivo.

\section{Cuidado do outro, cuidado de si}

No hospital em questão coexistem três tipos de vínculo de trabalho: um estatutário, um com carteira assinada por empresas terceirizadas e um terceiro, formalizado por um contrato de prestação de serviço autônomo, que é menos estável e que contempla menos direitos trabalhistas do que um 
contrato de carteira assinada, como, por exemplo, o não pagamento de $13^{\circ}$ salário ou $1 / 3$ de férias. Desde o conhecimento sobre esse vínculo precário de trabalho entre o hospital e parcela significativa dos profissionais da UTI (62\%), uma questão se colocou para nós: o que garante a estabilidade do serviço prestado nessa UTI? Uma pista e abertura para a produção de novas questões foi trazida pelos participantes do EsT7, quando afirmaram: "apesar de tudo, a gente vem pro trabalho porque temos compromisso com ele". Estariam eles apontando apenas para um compromisso formal, do tipo estabelecido no contrato de trabalho? Ou para a adesão a um conjunto de regras de trabalho com vistas à manutenção de seu pertencimento no coletivo, ou no ofício? Mesmo considerando as influências sociais que determinam em parte a atividade humana, acreditamos que essa afirmação de compromisso não pode ser entendida genericamente, sem levar em conta as microescolhas, os diferentes usos de si, que se operam nas atividades de trabalho ${ }^{11}$. Dentre eles, os que se efetuam a partir do debate entre normas de cuidado de si e normas de cuidado do outro, se permitindo mais ou menos afetar-se pelo sofrimento alheio.

Excerto dos diálogos no EsT 3:

- Precisamos entender a situação de fragilidade dos responsáveis. Às vezes nem foram para casa, não têm o que comer, não têm nada fora para fazer. A cadeira de descanso é desconfortável. A nossa relação com os pais das crianças influencia no modo como nos relacionamos com as crianças. Algumas vezes a antipatia que sentimos por alguns pais é transferida para a criança que é filha. - Mas isso não é certo.

Fizeram também referência a uma flutuação entre emoções positivas e negativas ao longo de uma jornada de trabalho: "ficar feliz por uns, triste por outros" (Excerto dos diálogos no EsT 3). Indicaram que em alguns casos, infringem não apenas as normas do hospital, mas as suas próprias, reportando, via celular, informações e fotos a alguns responsáveis que não podem acompanhar os pacientes ininterruptamente. Nesses embates entre normas antecedentes e entre elas e as normas de vida, valores são convocados, sobretudo os referentes ao bem comum, os quaisnão são dimensionáveis ou hierarquizáveis, como, por exemplo, o bem-estar dos pacientes e familiares, o acesso igualitário aos cuidados, a saúde dos pacientes e a sua própria, a justiça e a solidariedade. Valores esses que podem em situações específicas estar em oposição entre si, produzindo um debate/embate permanente de normas diante das situações concretas de trabalho.

\section{Excerto dos diálogos no EsT 2:}

- Acho prejudicial essa ligação porque a gente não se desvincula dos pacientes. - A denominação "meu paciente", o vínculo de posse pelo amor, parte de cada um deles faz parte de nós. - Mas o apego muito intenso, preocupação intensa é prejudicial para a saúde. Ficar muito no trabalho e pouco em casa faz esse processo te tornar família de um paciente. 
Há maior afinidade com alguns pacientes, mas é necessário o cuidado ser igual. Pensar que algumas mortes são justas e outras não, o quão estranho é isso.

A última frase desse trecho de diálogo - "pensar que algumas mortes são justas outras não" - não foi objeto de discussão durante o EsT, não nos autorizando a afirmar que normas estariam em jogo. Todavia, ao convocar o valor justiça, nos permitiu colocar em questão se podemos dizer antecipadamente como deveríamos escolher/decidir em um momento específico, sem atribuir a esse valor alguma dimensão ou hierarquização em relação a outros valores que podem estar em jogo. Schwartz ${ }^{11}$ afirma que é impossível dar realidade aos valores do bem comum sem produzir um efeito sobre valores dimensionáveis. Isto é, seria impossível operar com o valor justiça no serviço público de saúde sem colocar em questão a alocação dos recursos monetários disponíveis para tal. E vice-versa! Nesse sentido, o autor afirma a diferença entre subordinação jurídica e subordinação pessoal, chamando a atenção de que é na atividade humana que se dá a confrontação entre a gestão que os trabalhadores fazem em seu trabalho e a gestão do trabalho que se pretende via indicadores gerenciais.

\section{Entidades coletivas relativamente pertinentes}

Também nos serviços públicos de saúde os sistemas de avaliação do trabalho, tendencialmente, têm privilegiado critérios e valores dimensionáveis, contribuindo para a invisibilidade das gestões efetuadas nos debates/embates de normas. No início do primeiro EsT o médico chefe da UTI informou sobre o resultado de uma pesquisa de satisfação dos responsáveis em relação ao serviço prestado na UTI, que fora classificado como regular. A partir de um exemplo de uma mãe que identificou e alertou a equipe sobre os motivos do filho não estar ganhando peso, ele propôs, em um discurso prescritivo, que os profissionais buscassem sair do lugar de sapiência e ouvir os responsáveis, ao que obteve a concordância da maioria dos presentes (médicos e residentes). Até que, pedindo desculpas - como que por quebrar uma regra de não aprofundar o debate sobre as dificuldades que envolvem o trabalhar junto -, uma enfermeira contestou a fala do médico indicando que ela generalizava a postura de não escuta ao que os responsáveis teriam a dizer sobre o trabalho realizado na UTI:

Excerto dos diálogos do EsT 1:

- Nós da enfermagem já sabíamos e já tínhamos falado sobre isso há muito tempo e vocês não ouviram. Às vezes nós não somos ouvidos. Essa comunicação devia melhorar. É muito ruim quando a gente fala sozinho e ninguém quer ouvir. Às vezes a gente só tá ouvindo e não prestando atenção. Só riem. [silêncio]

Os outros estão sempre presentes no trabalho, seja através da preparação, da prescrição, do uso ou em sua avaliação. Schwartz ${ }^{18}$ registra a presença de uma processualidade plástica e eventual 
que denomina entidades coletivas relativamente pertinentes (ECRP). Propõe o termo "entidade" para referir-se a ligações de transição dinâmica, ou seja, grupalidades de contornos fluidos, cujas fronteiras são invisíveis, englobando pessoas e serviços diferentes, onde a cooperação não está prevista. Já a qualificação de "relativamente pertinentes" é para ressaltar que elas não funcionam somente segundo a divisão formal do trabalho (organograma), mas também pela força de coesão produzida no trabalho coletivo e dos valores compartilhados pelos seus integrantes. Neste sentido, a pertinência não é uma condição para que funcione, isto é, ela é avaliada segundo o grau de asseguramento do trabalho coletivo.Entretanto, o trabalhar junto requer um complexo ajustamento recíproco das gestões/escolhas que cada um realiza diante das situações concretas. Assim, esse cooperar - que muitas vezes envolve a atividade dos responsáveis pelos pacientes da UTI -, não se faz por decretos, regras ou prescrições. Muito menos sem a construção de espaços de diálogo sobre o trabalho (real) que se faz junto.

\section{Excerto dos diálogos no EsT 1:}

- Me sinto melhor trabalhando na ausência dos pais, por eles não compreenderem certas práticas e procedimentos. Quando eles estão presentes, me sinto vigiado (médico). - Eu não me incomodo. Me sinto segura, mas há muita comparação entre os colegas ao olhar dos pais (téc. enf). - Geralmente as crianças retornam para a UTI e os pais têm dificuldade de entender que aqui os processos são diferentes dos do ambulatório. Os pais acham que sabem mais e melhor sobre os filhos do que a gente. Reclamam fazendo comparações. Estão o tempo todo com a criança, não dando espaço para um contato apenas equipe-criança. Os pais se sentem desconfortáveis com os procedimentos que tendem a ser invasivos, eles descarregam o estresse na gente: "você mexeu no meu filho, mexeu nele e ele descompensou" (enfermeira). - Chegamos para fazer os cuidados e o pai disse: "não, hoje você só troca a fralda do meu filho" (téc. enf.).

A partir do debate sobre o caráter situado e singular das atividades de trabalho realizadas, e reconhecendo a necessidade da cooperação dos responsáveis para o trabalho de cuidado das crianças-pacientes, uma técnica indicou a estratégia que usa para tornar essa cooperação possível: "Se impor, mostrar respeito, mas também fazer com que seja possível agregá-los" (Excerto dos diálogos no EsT2). Destaca a importância de explicar os procedimentos técnicos de forma compreensível e de construir uma relação de confiança, indicando que cada situação de trabalho, com cada paciente, familiar e ou colegas de distintas formações e ofícios, traz aos profissionais da UTI o desafio e a possibilidade de reaprendizado em seu trabalho.

Segundo Schwartz ${ }^{11}$, é nas renormatizaçõesque se fabricam as ECRPs. E estas se apresentam como uma condição de eficácia e saúde no trabalho, pois que permitem dar espaço a esses debates de normas,com suas reservas de alternativas. Dentre os tantos debates de normas entre o desejo 
de preservação de sua saúde mental e o respeito pela dor alheia (dos pacientes e responsáveis), algumas reservas de alternativas se produzem nas renormatizações efetuadas pelas ECRPs. Dentre elas, o uso de um espaço da UTI restrito aos profissionais de saúde para compartilhar com os colegas de trabalho experiências alegres de situações da vida no trabalho e, principalmente, fora do trabalho, como viagens, festas, atividades esportivas, etc. Assuntos esses, entendidos por eles como potencialmente desrespeitosos em relação à dor dos pacientes e familiares ali presentes, devendo assim ser evitados no espaço da UTI compartilhado com eles. Entendemos que essa regra - que por ventura possamos qualificar como uma regra do ofício - representa um ato de saúde e de produção de uma vida coletiva em que valores como respeito, solidariedade e compaixão são afirmados por esse coletivo. Todavia, vale ressaltar que somente a presença contínua dos graduandos no espaço de trabalho da UTI, permitindo uma aproximação tal com o trabalho real dos profissionais que lá atuam, nos possibilitou formular essa hipótese. Foi em uma situação cotidiana de comemoração de aniversário de um profissional, em que um dos graduandos foi convidado a compartilhar desse espaço, que ele - dada a diferença entre os temas de modos de abordá-los nos diálogos travados entre os profissionais e entre estes e o graduando - denominou de "armário de Nárnia", fazendo alusão à obra literáriade C. S. Lewis intitulada "As crônicas de Nárnia" - cujos volumes foram publicados entre os anos de 1950 e 1956 - na medida em que, segundo o graduando, "parecia outro mundo", já que era um espaço dentro da UTI onde se falava sobre tudo, menos sobre o trabalho.

\section{CONSIDERAÇÕES FINAIS}

Atentos para não subestimar o modo como as experiências de vida, os valores, se articulam às dinâmicas da atividade estudadas ${ }^{19}$, buscou-se nessa ação de extensão refletir coletivamente sobre como os profissionais gerem as situações, mobilizando e retrabalhando sua experiência, seus saberes, suas competências de vida. Ao fomentar a explicitação de alguns dos debates de normas e valores efetuados nas atividades de trabalho, acredita-se ter contribuído para iniciar uma interpretação conjunta da situação em que se encontram e potencialmente para a construçãode ações concretas de transformação do trabalho. Dizemos potencialmente porque entre o caráter formador dessa experiência -no sentido de produção de sentido sobre o vivido - e a efetivação de ações concretas de transformação das condições e modos de organização do trabalho, há que se reconhecer alguns limites dessa ação de intervenção.

Um deles foi o tempo necessário para a construção do dispositivo. O tempo necessário para que cada um naqueles encontros fosse conduzido a se interrogar sobre certas certezas e práticas. $\mathrm{O}$ tempo necessário para a construção de uma demanda de transformação do trabalho pelo coletivo que fizesse valer o risco de dar visibilidade aos múltiplos debates em que se jogam cotidianamente a eficácia e a vida em saúde no trabalho.Assim como o tempo e as condições necessárias para se produzir um diálogo-debate crítico e transformador acerca das condições e organização do trabalho. Em relação ao propósito de consecução de algumas ações de transformação concretas do 
trabalho - como, por exemplo, o espaço físico - seria necessário a instauração de uma discussão mais ampliada sobre as relações entre o trabalho na UTI e a saúde dos profissionais em outros níveis hierárquicos e instâncias políticas do hospital.

Listar as dificuldades de construção e alcance do dispositivo não tem aqui o propósito de decretar sua inviabilidade ou impossibilidade em relação aos objetivos que se pretende de promoção da saúde no trabalho, mas de chamar a atenção para aspectos que, apesar de não serem facilmente contornáveis em uma ação de intervenção, devem ser continuamente perseguidos. A apropriação pelos trabalhadores de conceitos e métodos ferramentas de análise do trabalho pode ser um passo importante para que, em um contexto mais propício, eles próprios possam operar o dispositivo. Entende-se que essa pode ter sido uma importante contribuição.

Por fim, ressaltam-se as repercussões positivas dessa ação de extensão no processo formativo dos estudantes envolvidos, tanto pela oportunidade que se teve de um processo de aprendizagem mútua com profissionais com diferentes formações e saberes técnico-científicos e da experiência, quanto pela possibilidade de aprendizado de mobilização de conceitos e teorias na construção do dispositivo e na reflexão sobre essa experiência.

Contribuição das autoras: As autoras contribuíram em todas as fases do trabalho, incluindo delineamento e execução da intervenção, assim como na análise dos dados e na redação do texto. As ações do projeto foram coordenadas e supervisionadas pela primeira autora.

\section{REFERÊNCIAS BIBLIOGRÁFICAS}

1. Baasch D, Laner A. Os significados do trabalho em unidades de terapia intensiva de dois hospitais brasileiros. Ciênc. saúde coletiva [Internet]. 2011 [acesso em 2018 Set 11]; 16 (Suppl 1): 1105-1097. Disponível em: http://www.scielo.br/scielo.php?script=sci_arttext\&pid=S1413$81232011000700041 \& \operatorname{lng}=$ en.

2. Shimizu H E, Ciampone M H. Sofrimento e prazer no trabalho vivenciado pelas enfermeiras que trabalham em unidades de terapia intensiva em um hospital escola. Rev. esc. enferm. USP [Internet]. 1999 Mar [acesso em 2018 Set 14]; 33(1): 106-95. Disponível em: http://www. scielo.br/scielo.php?script=sci_arttext\&pid=S0080-62341999000100010\&lng=en. http://dx.doi. org/10.1590/S0080-62341999000100010.

3. Fachini J S, Scrigni A V, Lima R G. Sofrimento moral de trabalhadores de uma UTI pediátrica. Rev. Bioét. [Internet]. 2017 Abr [acesso em 2018 Set 11]; 25(1): 111122. Disponível em: http://www.scielo.br/scielo.php?script=sci_arttext\&pid=S1983$80422017000100111 \& \operatorname{lng}=\mathrm{en}$. 
4. Nery D, Toledo A M, Oliveira J S, Taciro C, Carregaro R. Análise de parâmetros funcionais relacionados aos fatores de risco ocupacionais da atividade de enfermeiros de UTI. Fisioter. Pesqui. [Internet]. 2013 Mar [acesso em 2018 Set 11]; 20(1): 76-82. Disponível em: http:// www.scielo.br/scielo.php?script=sci_arttext\&pid=S1809-29502013000100013\&lng=en.

5. Fogaça M, Carvalho W B, Cítero V A, Nogueira-Martins L A. Fatores que tornam estressante o trabalho de médicos e enfermeiros em terapia intensiva pediátrica e neonatal: estudo de revisão bibliográfica. Rev. bras. ter. intensiva [Internet]. 2008 Set [acesso em 2018 Set 11]; 20(3): 261-266. Disponível em: http://www.scielo.br/scielo.php?script=sci arttext\&pid=S0103-507X2008000300009\&lng=en.

6. Hubault, F. L'approche ergonomique des questions santé/travail.Mouvements [Internet]. 2009 [acesso em 2010 Dez 12]; 2(58): 97-102. Disponível em: http:www.cairn.info/article. phpID_REVUE=MOUV\&ID_NUMPUBLIE=MOUV_058\&ID_ARTICLE=MOUV_058_0097.

7. Masson, L, Gomes, L, Brito, J. Encontros sobre o trabalho: reflexões sobre o uso dessa ferramenta metodológica em pesquisas em unidades de tratamento intensivo neonatais. Laboreal. 2015;11(1):23-38.

8. Canguilhem, G. Meio e normas do homem no trabalho. Proposições.2001;12(2-3): 35-36.

9. Canguilhem, G. O normal e o patológico. Rio de Janeiro: Forense Universitária; 2010.

10. Schwartz, Y. Trabalho e saúde: construindo outros modos de gestão. In: Mesa redonda no Congresso da ABRASCO; 2005 jul; Florianópolis, Brasil.

11. Schwartz, Y; Durrive, L, organizador. Trabalho e Ergologia: conversas sobre a atividade humana. 2. ed. Niterói: EDUFF; 2010.

12. Schwartz, Y; Durrive, L, organizador. Activité em dialogues: entretiens sur l'activité humaine II. Toulouse: Octarès; 2009.

13. Laurell AC, Noriega M. Processo de produção e saúde: trabalho e desgaste operário. São Paulo: Hucitec; 1989.

14. Oddone, I, RE, A, Brianti, G. Redécouvrir l'Expérience Ouvrière: vers une aoutre psychologie du travail? Paris: MessidorÉditionsSociales; 1981.

15. Schwartz, Y. Ergonomia, filosofia e exterritorialidade. In: Daniellou, F, editora. A ergonomia em busca de seus princípios. São Paulo: Edigard Blücher;2004,p. 180-141. 
16. Athayde, M, Zambroni-de-Souza, P, Brito, J. Intervenção e pesquisa em Psicologia: uma postura ergológica. In: Bendassolli, P, Soboll, L, organizadores. Métodos de pesquisa e intervenção em Psicologia do Trabalho. Clínicas do Trabalho. São Paulo: Editora Atlas; 2014.

17. Cru, D. Collectif e travail de metier: sur la notion de collectif de travail. Travailler.2016; 35(1): 53-59.

18. Schwartz, Y. Manifesto por um ergoengajamento. In: Bendassolli, P; Soboll, L, organizadores. Clínicas do trabalho: novas perspectivas para a compreensão do trabalho na atualidade. São Paulo: Atlas; 2011, p. 166-132.

19. Schwartz, Y. Intervenção, experiência e produção de saberes. Serviço Social e Saúde [Internet]. 2015Maio [acesso em 18 set. 2018]; 10(2): 19-43. Disponível em: https://periodicos. sbu.unicamp.br/ojs/index.php/sss/article/view/8634834.

Artigo apresentado em: dezembro de 2018

Artigo aprovado em: maio 2019 Conflito de interesses: as autoras declaram não haver conflito de interesses. Suporte financeiro: PROFAEX / UFRJ 